\title{
Some Boundary Value Problems for the Hyperbolic: Hyperbolic type Equation with Two Line of Degeneration in Special Domain
}

\section{Abdullayev $\mathbf{O} \mathbf{K h}^{*}$}

National University of Uzbekistan, Almazar District, Tashkent, Uzbekistan

\author{
Abstract \\ In the present paper we study unique solvability of the analogues of problem Bitsadze for the degenerating \\ hyperbolic-hyperbolic type equation. Uniqueness and existence theorem for solution of this problems are proven with \\ principle extremum and by the method of integral equations.
}

Keywords: Boundary value problem; Existence and uniqueness of solution; Degenerating equation; Hyperbolic-hyperbolic type; A principle an extremum; Method of integral equations

\section{Introduction}

Last years the increasing attention of mathematicians is involved with problems of correctness of the boundary value problems (BVP) for the degenerating equations of the mixed parabolic-hyperbolic, elliptichyperbolic and hyperbolic-hyperbolic types. It is closely connected with appendices of such problems to the decision of problems of mechanics, gas dynamics, biology and in other material sciences. The first basic researches under the theory of the degenerating equations of the mixed and mixed-compound type are Trikomi's [1], Gellerstedt's et al, [2], Bitsadze's [3] and Salakhitdinov's [1,4,5] works. The degenerating and singularity equations possess that nature, that for them the correctness of some classical problems not always takes place. This fact rather for the degenerating equations of elliptic type, in the first has been noticed of MKeldych [6], and concerning the degenerating equations of hyperbolic type of Gellerstedt. In this cases Bitsadze has suggested to study modify problems Cauchy for the degenerating equation of hyperbolic type because the problems Cauchy for such equations it is put incorrectly. Since Bitsadze's [2] works, in the theory partial differential equations there was a new direction, in which the analogue of problem Tricomi for the first time is formulated and investigated in double connected domain for the modeling equations of the mixed type. After this work various problems for the equation of the mixed type on the second order in multiply and doubly connected domains are investigated, in works as Bers [3] and Salahitdinov, Urinov [1,5]. However, BVPs in double-connected domain are studied for the not degenerated modeling equations of the third order of elliptichyperbolic type [7], and uniqueness of solution of the problem for the degenerated hyperbolic-hyperbolic type equation in double-connected domain was proved by Islomov et al. [4].

\section{The Statement of Problems}

In the present work the analogues of problem A.V. Bitsadze [2] is formulated and investigated for the hyperbolic-hyperbolic type equation with two degenerating lines of the following kind:

$$
(-\mathrm{y})^{\mathrm{n}} \mathrm{u}_{\mathrm{xx}}-|x|^{n} u_{y y}=0, n=\text { const }>0
$$

in the special domain $\Omega$, bounded at $\mathrm{y}<0$ with characteristics

$$
\begin{aligned}
& A_{j} C_{1}:\left((-1)^{\mathrm{j}-1} \mathrm{x}\right)^{\frac{n+2}{2}}+(-\mathrm{y})^{\frac{n+2}{2}}=q^{\frac{n+2}{2}} ;(\mathrm{j}=1,2) \\
& B_{j} C_{2}:\left((-1)^{\mathrm{j}-1} \mathrm{x}\right)^{\frac{n+2}{2}}+(-\mathrm{y})^{\frac{n+2}{2}}=1 ;(\mathrm{j}=1,2),(0<\mathrm{q}<1)
\end{aligned}
$$

of the equation ( 1 , and at $\mathrm{y}=0$ with segments $\mathrm{A}_{j} \mathrm{~B}_{j}$ where $A_{j}\left((-1)^{\mathrm{j}-1} q ; 0\right)$ $B_{j}\left((-1)^{\mathrm{j}-1} ; 0\right),(\mathrm{j}=1,2)$.

\section{We introduce the following notations:}

Through $\Omega_{1 j}$ and $\Omega_{3 j}$ we will designate characteristic triangles $A_{j} B_{j} E_{j}$ and $\mathrm{C}_{1} \mathrm{~F}_{\mathrm{j}} \mathrm{C}_{2}(\mathrm{j}=1,2)$, accordingly, and through $\Omega_{2 \mathrm{j}}$ we will designate characteristic quadrangles $\mathrm{A}_{j} \mathrm{E}_{j} \mathrm{~F}_{\mathrm{j}} \mathrm{C}_{1}(\mathrm{j}=1,2)$. In the section 2 we have formulated and proved unique solvability of a problems $I\left(\mathrm{I}^{*}\right)$ and II $\left(\mathrm{II}^{*}\right)$ in the domain of, which, consist of four characteristic triangles and from two quadrangles. The result, which is obtained in this section shows that when we will investigate problems $\mathrm{I}\left(\mathrm{I}^{*}\right)$ and $\mathrm{II}\left(\mathrm{II}^{*}\right)$, in each sub domains, we find the solution of equation (1)in an explicit form In the section 3 we studying uniqueness and existence of solution of a problem III $\left(\right.$ III $\left.^{*}\right)$. Uniqueness of solution of problem III $\left(\right.$ III $\left.^{*}\right)$ are proven with principle an extremum. Existence of the solution of problem III (III*) we have proved, by method integral equations. The main result of this section shows that when we will studying existence of the solution of problem III(III*), we have singularity integral equation, which regularities by the method of Karleman'sVekua [8], to the integral equation of Fredgolm of the second kind.

\section{Unique solvability of the problems $\mathrm{I}\left(\mathrm{I}^{*}\right)$ and $\mathrm{II}\left(\mathrm{II}{ }^{*}\right)$}

Problem I: Find a function $\mathrm{u}(\mathrm{x}, \mathrm{y})$ in the domain $\Omega$ with following properties:

1) $u(\mathrm{x}, \mathrm{y}) \in \mathrm{C}(\bar{\Omega}) \cap \mathrm{C}^{2}(\Omega)$;

2) $\mathrm{u}(\mathrm{x}, \mathrm{y})$ satisfies the equation (1) in domains $\Omega_{1 \mathrm{j}}, \Omega_{2 \mathrm{j}}, \Omega_{3 \mathrm{j}}(\mathrm{j}=1,2)$;

3) $u(x, y)$ satisfies the following conditions

$$
\begin{aligned}
& u(\mathrm{x}, 0)=\tau_{\mathrm{j}}(\mathrm{x}), \mathrm{x} \in \overline{\mathrm{A}_{\mathrm{j}} \mathrm{B}_{\mathrm{j}}} \\
& \left.u(\mathrm{x}, \mathrm{y})\right|_{B_{1} C_{2}}=\varphi(\mathrm{x}), \mathrm{x} \in[0,1] \\
& \left.u(\mathrm{x}, \mathrm{y})\right|_{A_{2} C_{1}}=\psi(\mathrm{x}), \mathrm{x} \in[-\mathrm{q}, 0]
\end{aligned}
$$

*Corresponding author: Abdullayev $\mathrm{O} \mathrm{Kh}$, National University of Uzbekistan, Almazar District, Tashkent, Uzbekistan, Tel: 998(71)1145236, +998(71) 246-0220; E-mail: obidjon.mth@gmail.com

Received March 29, 2014; Accepted April 28, 2014; Published May 05, 2014

Citation: Kh AO (2014) Some Boundary Value Problems for the Hyperbolic: Hyperbolic type Equation with Two Line of Degeneration in Special Domain. J Appl Computat Math 3: 163 doi:10.4172/2168-9679.1000163

Copyright: ( 2014 Melnikov YA. This is an open-access article distributed under the terms of the Creative Commons Attribution License, which permits unrestricted use, distribution, and reproduction in any medium, provided the original author and source are credited. 
Where $\mathrm{T}_{\mathrm{j}}(\mathrm{x}), \varphi(\mathrm{x}), \Psi(\mathrm{x})$ - given functions, and $\tau_{j}(\mathrm{x}) \in \mathrm{C}\left(\overline{\mathrm{A}_{\mathrm{j}} \mathrm{B}_{\mathrm{j}}}\right) \cap \mathrm{C}^{3}\left(\mathrm{~A}_{\mathrm{j}} \mathrm{B}_{\mathrm{j}}\right)$,

$$
\begin{aligned}
& \tau_{1}(1)=\varphi(1), \tau_{2}(-q)=\psi(-\mathrm{q}) \\
& \varphi(\mathrm{x}) \in \mathrm{C}[0,1] \cap C^{3}(0,1) \psi(\mathrm{x}) \in \mathrm{C}[-q, 0] \cap C^{3}(-\mathrm{q}, 0)
\end{aligned}
$$

Problem I*: Find a function $\mathrm{u}(\mathrm{x}, \mathrm{y})$ in domain $\Omega$, satisfies to all conditions problem $I$, except $(2)(j=1,2)$ which are replaced with conditions

$$
u_{y}(\mathrm{x}, 0)=\mathrm{v}_{\mathrm{j}}(\mathrm{x}), \mathrm{x} \in \mathrm{A}_{\mathrm{j}} \mathrm{B}_{\mathrm{j}}
$$

where $\mathrm{v}_{\mathrm{j}}(\mathrm{x})$ - given functions, and

$$
\mathrm{v}_{\mathrm{j}}(\mathrm{x}) \in C^{2}\left(\mathrm{~A}_{\mathrm{j}} \mathrm{B}_{\mathrm{j}}\right),(\mathrm{j}=1,2)
$$

Problem II (II'): Find a function $\mathrm{u}(\mathrm{x}, \mathrm{y})$ in domain $\Omega$, satisfies to all conditions problem $\mathrm{I}\left(\mathrm{I}^{*}\right)$, except (3), (4) which are replaced with conditions:

$$
u \mid B_{j} E_{j}=\mu_{\mathrm{j}}(\mathrm{x}), \mathrm{x} \in \overline{B_{j} E_{j}}
$$

And

$$
u \mid A_{j} C_{1}=\psi_{\mathrm{j}}(\mathrm{x}), \mathrm{x} \in \overline{A_{j} C_{1}}
$$

where $\mu_{j}(\mathrm{x}), \Psi_{j}(\mathrm{x})$ - given functions, and:

$$
u_{j}(\mathrm{x}) \in \mathrm{C}\left(\overline{B_{j} E_{j}}\right) \cap \mathrm{C}^{3}\left(B_{j} E_{j}\right), \psi_{\mathrm{j}}(\mathrm{x}) \cap \mathrm{C}\left(\overline{A_{j} C_{1}}\right) \cap \mathrm{C}^{3}\left(\overline{A_{j} C_{1}}\right)
$$

Theorem 1: If conditions $\left(5_{\mathrm{j}}\right)\left(\left(5_{2}\right)\right.$ and $\left.\left(7_{\mathrm{j}}\right)\right)$ are satisfied that the problem $\mathrm{I}\left(\mathrm{I}^{*}\right)$ is unique solvability.

Proof: Is known, that the solution of problem Cauchy in domain $\Omega_{11}$ for the equation (1) satisfying to conditions $\left(2_{1}\right)$ and $\left(6_{1}\right)$ looks like $[8,9]$ :

$$
\begin{aligned}
& u(\mathrm{x}, \mathrm{y})=\gamma_{1} \int_{q}^{1} \tau 1\left(\mathrm{z}_{1}^{\frac{1}{n+2}}\right)[(\mathrm{t}-\mathrm{q})(1-\mathrm{t})]^{\beta-1} d t \\
& -\gamma_{2} x y \int_{q}^{1} v\left(\mathrm{z}_{1}^{\frac{1}{n+2}}\right) \mathrm{z}_{1}^{-\frac{1}{n+2}}[(\mathrm{t}-\mathrm{q})(1-\mathrm{t})]^{-\beta} d t
\end{aligned}
$$

Where

$$
z_{1}=x^{n+2}+(-\mathrm{y})^{\mathrm{n}+2}+\frac{2(2 \mathrm{t}-\mathrm{q}-1)}{1-q}(-\mathrm{xy}) \frac{\mathrm{n}+2}{2}, \gamma_{1}=\frac{\Gamma(2 \beta)(1-\mathrm{q})^{1-2 \beta}}{\Gamma^{2}(\beta)} \gamma_{2}=\frac{\Gamma(2 \beta)(1-\mathrm{q})^{1-2 \beta}}{\Gamma^{2}(1-\beta)}
$$

From here, by virtue condition (3), considering (51) ((71)) it is easily possible to define unknown function $\mathrm{v}_{1}(\mathrm{x})\left(\mathrm{T}_{1}(\mathrm{x})\right)$, hence, owing to uniqueness of the solution of problem Cauchy, the solution of the problem $\mathrm{I}\left(\mathrm{I}^{*}\right)$ in domain $\Omega_{11}$ is uniquely defined.

Further, designating through $\mathrm{h}_{1}(\mathrm{x})$ a trace of the solution of problem Cauchy- Gaursat 1 (Cauchy-Gaursat 2) from domain $\Omega_{11}$ on the characteristic $\mathrm{A}_{1} \mathrm{E}_{1}$ and considering the condition (3) taking into account $\left(5^{2}\right)$, by the method of Riemann, we restore the solution of the problem $\mathrm{I}\left(\mathrm{I}^{*}\right)$ in domain the of $\Omega_{21}$ as the solution of problem Gaursat and this solution is given by the formula:

$$
\begin{aligned}
& u(\xi, \eta)=-2 \beta \int_{\xi}^{q^{\frac{n+2}{2}}} \varphi^{*}\left(\left(\frac{t+1}{2}\right)^{1-2 \beta}\right) \frac{t\left(\mathrm{t}^{2}-1\right)^{1-2 \beta}}{\left(\mathrm{t}^{2}-\mathrm{n}^{2}\right)^{\beta}\left(\xi^{2}-1\right)^{\beta}} F(\beta, \beta, 1 ; \sigma) d t \\
& -\int_{\eta}^{1} d\left[\left(\mathrm{~h}_{1}\left(\frac{q^{(\mathrm{n}+2) / 2}+t}{2}\right)^{1-2 \beta}\right)\right] \frac{\left(\mathrm{q}^{n+2}-t^{2}\right)^{2 \beta}}{\left(\xi^{2}-t^{2}\right)^{\beta}\left(\mathrm{q}^{n+2}-\eta^{2}\right)^{\beta}} F(\beta, \beta, 1 ; \sigma) d t+ \\
& +2 \beta \int_{\eta}^{1}\left(\mathrm{~h}_{1}\left(\frac{q^{(\mathrm{n}+2) / 2}+t}{2}\right)^{1-2 \beta}\right) \frac{\mathrm{t}\left(\mathrm{q}^{n+2}-t^{2}\right)^{2 \beta-1}}{\left(\xi^{2}-t^{2}\right)^{\beta}\left(\mathrm{q}^{n+2}-\eta^{2}\right)^{\beta}} F \cdot(\beta, \beta, 1 ; \sigma) d t
\end{aligned}
$$

$$
\begin{aligned}
& -\int_{\eta}^{q^{(\mathrm{n}+2) / 2}} d\left[\varphi^{*}\left(\left(\frac{t+1}{2}\right)^{1-2 \beta}\right)\right] \frac{\left(\mathrm{t}^{2}-1\right)^{2 \beta}}{\left(\xi^{2}-1\right)^{\beta}\left(t^{2}-\eta^{2}\right)^{\beta}} F(\beta, \beta, 1 ; \sigma) d t \\
& +\mathrm{h}_{1}\left(\left(\frac{q^{(\mathrm{n}+2) / 2}+t}{2}\right)^{1-2 \beta}\right) \frac{\left(\mathrm{q}^{n+2}-1\right)^{2 \beta-1}}{\left(\xi^{2}-1\right)^{\beta}\left(\mathrm{q}^{n+2}-\eta^{2}\right)^{\beta}} F\left(\beta, \beta, 1 ; \frac{\left(\xi^{2}-\mathrm{q}^{n+2}\right)\left(1-\eta^{2}\right)}{\left(\xi^{2}-1\right)^{\beta}\left(\mathrm{q}^{n+2}-\eta^{2}\right)}\right)
\end{aligned}
$$

Where

$$
\sigma=\frac{\left(\xi^{2}-\mathrm{t}^{2}\right)\left(1-\eta^{2}\right)}{\left(\xi^{2}-1\right)\left(t^{2}-\eta^{2}\right)}, \sigma_{1}=\frac{\left(\xi^{2}-q^{n+2}\right)\left(t^{2}-\eta^{2}\right)}{\left(\xi^{2}-t^{2}\right)\left(q^{n+2}-\eta^{2}\right)}
$$

Similarly, we find the unique solution of problem Gaursat for the equation (1) in domain $\Omega_{31}$ in an explicit form. As the solution $\mathrm{u}(\mathrm{x}, \mathrm{y})$ is found in domain $\Omega_{31}$ an obvious kind, can write out the solution of problem Cauchy for the equation (1) in domain $\Omega_{32}$ too. Hence, in domains $\Omega_{22}$ and $\Omega_{12}$ the solution of problem $\mathrm{I}\left(\mathrm{I}^{*}\right)$ is restored as the solution of problem Gaursat and Cauchy-Gaursat-1 (Cauchy-Gaursat-2) accordingly. The theorem is proved. Theorem 2. If conditions (51) and (10) ((7) and (10)) are satisfied that the problem II (II) is unique solvability. The theorem 2 is proved similarly as the theorem 1.

\section{Uniqueness and Existence of Solutions of the Problem III (III)}

Problem III (III): Find a function $\mathrm{u}(\mathrm{x}, \mathrm{y})$ in domain $\Omega$ satisfies to all conditions problem $\mathrm{I}\left(\mathrm{I}^{*}\right)$,except (3) which are replaced with conditions:

$$
\begin{aligned}
& u \mid B_{1} E_{1}=\varphi^{*}(\mathrm{x}), \mathrm{x} \in\left[\frac{1-q}{2}, 1\right], \\
& u \mid F_{2} C_{2}=\psi^{*}(\mathrm{x}), \mathrm{x} \in\left[\frac{q-1}{2}, 0\right],
\end{aligned}
$$

where $\varphi^{*}(\mathrm{x}), \Psi^{*}(\mathrm{x})$ - given functions, and

$$
\varphi^{*}(\mathrm{x}) \in \mathrm{C}\left[\frac{1-q}{2}, 1\right] \cap C^{3}\left(\frac{1-q}{2}, 1\right), \psi^{*}(\mathrm{x}) \in \mathrm{C}\left[\frac{q-1}{2}, 0\right] \cap C^{3}\left(\frac{q-1}{2}, 0\right)(
$$

Theorem 3: If conditions $\left(5_{1}\right)$ and (15) $\left(\left(7_{i}\right)\right.$ are satisfied and (15)) that solution of a problem III (III) exists and is unique.

Proof: Is known, that the solution of problem Cauchy in $\Omega_{31}\left(\Omega_{32}\right)$ for the equation (1), satisfying to conditions $u(0, y)=\tau_{3}(y), \mathrm{y} \in \overline{C_{1} C_{2}}$ and $u_{x}(0, y)=v_{3}(y), y \in C_{1} C_{2}$ looks like:

$$
\begin{aligned}
& u(\mathrm{x}, \mathrm{y})=\gamma_{1} \int_{-1}^{-q} \tau_{3}\left(\mathrm{z}_{1}^{\frac{1}{n+2}}\right)[(-\mathrm{t}-\mathrm{q})(1+\mathrm{t})]^{\beta-1} d t- \\
& -\gamma_{2} x y \int_{-1}^{-q} v_{3}\left(\mathrm{z}_{1}^{\frac{1}{n+2}}\right) \mathrm{z}_{1}^{-\frac{1}{n+2}}[(-\mathrm{t}-\mathrm{q})(1+\mathrm{t})]^{\beta-1} d t \\
& \left(u(\mathrm{x}, \mathrm{y}) \gamma_{1} \int_{-1}^{-q} \tau_{3}\left(\mathrm{z}_{3}^{\frac{1}{n+2}}\right)[(-\mathrm{t}-\mathrm{q})(1+\mathrm{t})]^{\beta-1} d t-\gamma_{2} x y \int_{-1}^{-q} v_{3}\left(\mathrm{z}_{3}^{\frac{1}{n+2}}\right)[(-\mathrm{t}-\mathrm{q})(1+\mathrm{t})]^{\beta-1} d t,\right) \\
& z_{3}=(-\mathrm{x})^{\mathrm{n}+2}+(-\mathrm{y})^{\mathrm{n}+2}+\frac{2(2 \mathrm{t}-\mathrm{q}-1)}{1-q}(\mathrm{xy})^{\frac{n+2}{2}}
\end{aligned}
$$

Where

$$
\gamma_{1}=\frac{\Gamma(2 \beta)(1-\mathrm{q})^{1-2 \beta}}{\Gamma^{2}(\beta)}, \gamma_{2}=\frac{\Gamma(2-2 \beta)(1-\mathrm{q})^{2 \beta-1}}{\Gamma^{2}(1-\beta)}
$$


Citation: Kh AO (2014) Some Boundary Value Problems for the Hyperbolic: Hyperbolic type Equation with Two Line of Degeneration in Special Domain. J Appl Computat Math 3: 163 doi:10.4172/2168-9679.1000163

Page 3 of 4

From here, owing to condition $\left.u(x, y)\right|_{C_{1} F_{1}}=h_{2}(y)$ and (14) taking into account properties of integro-differential operators of fractional order $[8,9]$ accordingly we will receive:

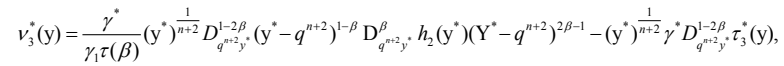

And

$$
v_{3}^{*}(\mathrm{y})=\frac{\gamma^{*}}{\gamma_{1} \tau(\beta)}\left(\mathrm{y}^{*}\right)^{\frac{1}{n+2}} D_{q^{2+2} y^{*}}^{1-2 \beta}\left(1-y^{*}\right)^{1-\beta} \mathrm{D}_{y^{\prime} 1}^{\beta} \psi^{*}\left(\mathrm{y}^{*}\right)\left(1-y^{*}\right)^{2 \beta-1}+\left(\mathrm{y}^{*}\right)^{\frac{1}{n+2}} \gamma^{*} D_{y^{\prime} 1}^{1-2 \beta} \tau_{3}^{*}(\mathrm{y}),
$$

where $h_{2}(y)$ - a trace of solution of the Gaursat in domain $\Omega_{21}$, satisfying condition (13) and

$$
\begin{aligned}
& \left.u(x, y)\right|_{A_{1} E_{1}}=h_{1}(x), \text { and } \gamma^{*}=\frac{\gamma_{1} \Gamma(\beta)}{\gamma_{2} \Gamma(1-\beta) 4^{2 \beta-1}}, \tau_{3}^{*}(\mathrm{y})=\tau\left(\left(\mathrm{y}^{*}\right)^{\frac{1}{n+2}}\right) \\
& v_{3}^{*}(\mathrm{y})=v\left(\left(\mathrm{y}^{*}\right)^{\frac{1}{n+2}}\right) \text { here } y^{*}=\left(2(-\mathrm{y}) \frac{n+2}{2}-1\right)^{2}
\end{aligned}
$$

At the proof of the theorem 3 takes place

Lemma: The solution $\mathrm{u}(\mathrm{x}, \mathrm{y})$ of the problem III $\left(\mathrm{III}^{*}\right)$ at

$$
\tau j(\mathrm{x}) \equiv \varphi^{*}(\mathrm{x}) \equiv \psi^{*}(\mathrm{x}) \equiv 0 v_{j}(\mathrm{x}) \equiv \varphi^{*}(\mathrm{x}) \equiv \psi^{*}(\mathrm{x}) \equiv 0,(\mathrm{j}=1,2)
$$

in the domain the positive maximum and negative minimum reaches only in points $\mathrm{C}_{1}$ and $\mathrm{C}_{2}$.

Proof: By virtue $\left(20_{\mathrm{j}}\right)$ and considering solutions of problem Cauchy-Gaursat (in the domain $\Omega_{11}$ ) and Gaursat (in the domain 21) for the equation ( 1 ) we will receive, that $\mathrm{u}(\mathrm{x}, \mathrm{y})=0$ on the characteristic $\mathrm{C}_{1} \mathrm{~F}_{1}$. From here, owing to a principle of extremum for the hyperbolic equations $[4,9,10]$ function $\mathrm{u}(\mathrm{x}, \mathrm{y})$ reaches the positive maximum and the negative minimum in the domain 31 only on the piece $\mathrm{C} 1 \mathrm{C} 2$. Similarly, owing to the principle of an extremum for the hyperbolic equations [10] with the account $\Psi^{*}(\mathrm{x}) \bigotimes 0$, we have, that the function $\mathrm{u}(\mathrm{x}, \mathrm{y})$ reaches the positive maximum and the negative minimum in domain $\Omega_{32}$ only on the piece $\mathrm{C}_{1} \mathrm{C}_{2}$.

Let function $\mathrm{u}(\mathrm{x}, \mathrm{y})$ reaches the positive maximum (the negative minimum) in some point $\mathrm{y}_{0}$ of the interval $\mathrm{C}_{1} \mathrm{C}_{2}$ (i.e. $\mathrm{y}_{0} €(-1,-\mathrm{q})$ ) then owing to (18) and (19) taking into account a principle of extremum for the integro-differential operators of fractional order [9], accordingly we will receive $\mathrm{u}_{\mathrm{x}}\left(+0, \mathrm{y}_{0}\right)<0, \mathrm{y}_{0} €(-1,-\mathrm{q})$, and $\mathrm{u}_{\mathrm{x}}(-0$, $\left.\mathrm{y}_{0}\right)>0, \mathrm{y}_{0} €(-1,-\mathrm{q})$. From here owing to continuity of solution $\mathrm{u}(\mathrm{x}, \mathrm{y})$ have received the contradiction, i.e., the function $\mathrm{u}(\mathrm{x}, \mathrm{y})$ does not reach the positive maximum (the negative minimum) in the interval $\mathrm{C}_{1} \mathrm{C}_{2}$. Hence, function $\mathrm{u}(\mathrm{x}, \mathrm{y})$ can reach the positive maximum (the negative minimum) only on points $\mathrm{C}_{1}$ and $\mathrm{C}_{2}$. The lemma is proved. As, $\mathrm{u}(\mathrm{x}$, $y)=0$ on the characteristic $\mathrm{C}_{1} \mathrm{~F}_{1}$ and $\mathrm{C}_{2} \mathrm{~F}_{2}$, we have that, $\mathrm{u}(\mathrm{x}, \mathrm{y})=0$ on the points $\mathrm{C}_{1}$ and $\mathrm{C}_{2}$. From here, owing to continuity of solution $\mathrm{u}(\mathrm{x}, \mathrm{y})$ in the domain of, the problem III (III) with zeroes dates, has only trivial solution, i.e. uniqueness of the solution of problem III (III*) is roved. Existence of the solution of the problem III (III*) is proved, by method integral equations.

$$
\begin{aligned}
& \text { From functional relation }
\end{aligned}
$$

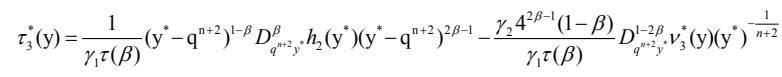

And

$$
\tau_{3}^{*}(\mathrm{y})=-\frac{1}{\gamma_{1} \tau(\beta)}\left(1-y^{*}\right)^{1-\beta} D_{y^{\prime}}^{\beta} \psi^{*}\left(\mathrm{y}^{*}\right)\left(1-\mathrm{y}^{*}\right)^{2 \beta-1}+\frac{\gamma_{2} 4^{2 \beta-1} \tau(1-\beta)}{\gamma_{1} \tau(\beta)} D_{y^{\prime} 1}^{2 \beta-1} v_{3}^{*}(\mathrm{y})\left(\mathrm{y}^{*}\right)^{-\frac{1}{n+2}}
$$

excluding $\tau_{3}^{*}(\mathrm{y})$ and considering properties of the integro-differential operators, we will receive singular integral equation. $v\left(\mathrm{y}^{*}\right)(1+\cos \pi(1-2 \beta))-\frac{\sin \pi(1-2 \beta)}{\pi} \int_{q^{1+2}}^{1}\left(\frac{1-t}{1-y^{*}}\right)^{1-2 \beta}\left(\frac{y^{*}}{t}\right)^{\frac{1}{n+2}} \frac{v(\mathrm{t})}{t-y^{*}} d t=\phi\left(\mathrm{y}^{*}\right)$

where

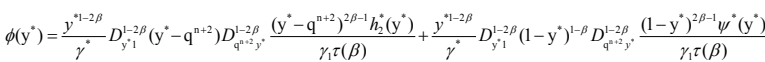

Entering designations, $a\left(y^{*}\right)=1+\cos \pi(1-2 \beta), b\left(y^{*}\right)=-i \sin \pi(1-2$ $\beta)$ and

$$
K\left(\mathrm{t}, \mathrm{y}^{*}\right)=\left(\frac{y^{*}}{t}\right)^{1-2 \beta}\left(\frac{1-t}{1-y^{*}}\right)^{1-2 \beta}-1,
$$

$$
a\left(\mathrm{y}^{*}\right) v\left(\mathrm{y}^{*}\right)+\frac{b\left(\mathrm{y}^{*}\right)}{\pi i} \int_{q^{n+2}}^{1} \frac{v(\mathrm{t})}{t-y^{*}} d t=\phi(y)-\frac{b\left(\mathrm{y}^{*}\right)}{\pi i} \int_{q^{n+2}}^{1} K\left(\mathrm{t}, \mathrm{y}^{*}\right) \frac{v(\mathrm{t})}{t-y^{*}} d t .
$$

We will estimate the function $\Phi\left(y^{*}\right)$, for this considering properties integro-differential operators, we have from (24)

$$
\begin{aligned}
& \phi\left(\mathrm{y}^{*}\right)=\frac{4^{1-2 \beta} y^{* 1-2 \beta}}{\gamma_{2} \tau(2 \beta) \tau^{2}(1-\beta)} \frac{d}{d y^{*}} \int_{\mathrm{y}^{*}}^{1} \frac{\left(t-q^{n+2}\right)^{1-\beta}}{\left(t-y^{*}\right)^{1-2 \beta}} d t \frac{d}{d t} \int_{q^{n+2}}^{1} \frac{\left(s-q^{n+2}\right)^{2 \beta-1}}{(t-s)^{\beta}} h 2(\mathrm{~s}) \mathrm{ds}+ \\
& \frac{4^{1-2 \beta} y^{*_{1}-2 \beta}}{\gamma_{2} \tau(2 \beta) \tau^{2}(1-\beta)} \frac{d}{d y^{*}} \int_{\mathrm{y}^{*}}^{1} \frac{(1-t)^{1-\beta}}{\left(t-y^{*}\right)^{1-2 \beta}} d t \frac{d}{d t} \int_{t}^{1} \frac{(1-s)^{2 \beta-1}}{(s-t)^{\beta}} \psi^{*} d s
\end{aligned}
$$

From here, having executed replacements $s=\left(t-q^{n+2}\right) z+q^{n+2}$ in first inner integral and $s=(1-t) z+t$ in second inner integral, we will receive:

$$
\begin{aligned}
& \phi\left(\mathrm{y}^{*}\right)=\frac{\beta \cdot 4^{1-2 \beta} y^{* 1-2 \beta}}{\gamma_{2} \tau(2 \beta) \tau^{2}(1-\beta)} \frac{d}{d y^{*}} \int_{\mathrm{y}^{*}}^{1}\left(t-y^{*}\right)^{2 \beta-1} \int_{0}^{1}(1-\mathrm{z})^{-\beta} z^{2 \beta-1} h_{2}^{*}(\mathrm{t}, \mathrm{z}) \mathrm{dzdt}+ \\
& \frac{4^{1-2 \beta} y^{* 1-2 \beta}}{\gamma_{2} \tau(2 \beta) \tau^{2}(1-\beta)} \frac{d}{d y^{*}} \int_{\mathrm{y}^{*}}^{1} \frac{t-q^{n+2}}{\left(t-y^{*}\right)^{1-2 \beta}} \int_{0}^{1}(1-\mathrm{z})^{-\beta} \mathrm{z}^{2 \beta} h_{2}^{* \prime}(\mathrm{t}, \mathrm{z}) \mathrm{dzdt}+ \\
& \frac{\beta .4^{1-2 \beta} y^{*_{1}-2 \beta}}{\gamma_{2} \tau(2 \beta) \tau^{2}(1-\beta)} \frac{d}{d y^{*}} \int_{\mathrm{y}^{*}}^{1}\left(t-y^{*}\right)^{2 \beta-1} \int_{0}^{1}(1-\mathrm{z}) z^{2 \beta-1} z^{1-\beta} \widetilde{\psi}^{\sim^{\prime}}(\mathrm{t}, \mathrm{z}) \mathrm{dzdt}+ \\
& \frac{4^{1-2 \beta} y^{*_{1}-2 \beta}}{\gamma_{2} \tau(2 \beta) \tau^{2}(1-\beta)} \frac{d}{d y^{*}} \int_{\mathrm{y}^{*}}^{1} \frac{t-t}{\left(t-y^{*}\right)^{1-2 \beta}} \int_{0}^{1}(1-\mathrm{z})^{2 \beta-1} \mathrm{z}^{1-\beta} h_{2}^{* \prime}(\mathrm{t}, \mathrm{z}) \mathrm{dzdt}
\end{aligned}
$$

where $h_{2}^{*}(\mathrm{t}, \mathrm{z})=h_{2}\left[\left(\mathrm{t}-\mathrm{q}^{\mathrm{n}+2}\right) \mathrm{z}+\mathrm{q}^{\mathrm{n}+2}\right] \quad$ and $\tilde{\psi}^{*}(\mathrm{t}, \mathrm{z})=\psi^{*}\left[\left(\mathrm{t}-\mathrm{q}^{\mathrm{n}+2}\right) \mathrm{z}+\mathrm{q}^{\mathrm{n}+2}\right]$. Hence, owing to properties $\mathrm{B}(\mathrm{a}, \mathrm{b})$ functions and taking into account a continuity of functions $h_{2}^{*}(\mathrm{t}, \mathrm{z}), h_{2}^{* \prime}(\mathrm{t}, \mathrm{z})$ and $\widetilde{\psi}^{*}(\mathrm{t}, \mathrm{z}), \psi^{* \prime}(\mathrm{t}, \mathrm{z})$ we will receive the estimate for function $\Phi\left(\mathrm{y}^{*}\right)$ :

$$
\left|\Phi\left(\mathrm{y}^{*}\right)\right| \leq \text { const. }\left(1-\mathrm{y}^{*}\right)^{2 \beta-1}
$$

As, $a^{2}\left(y^{*}\right)-b^{2}\left(y^{*}\right) \neq 0$ the integral equation (23) is singular integral equation of the normal type, and by virtue (27) and $\left|K\left(t, y^{*}\right)\right| \leq$ const $\cdot t^{1-2 \beta}$ $\left(1-y^{*}\right)^{2 \beta-1}$ we have that, index of integral equation (26), is equal to zero. Hence, by virtue of the theory singular integral equations and by the method regularities of Karlemens-Vekua [11], the integral equation (26) will be reduced to the integral equation of Fredgolm of the second kind with weak singularity. Thus, by virtue uniqueness of solution of the problem III(III*) the function $\mathrm{v}_{3}(\mathrm{y}) € \mathrm{C}(-1 ;-\mathrm{q}] \mathrm{C}^{2}(-1 ;-\mathrm{q})$ will be unequivocally find from the equation (26), and this function can have singularity of an order less than $1-2 \beta$ at the $y \rightarrow-1$ and continuous at $\mathrm{y} \rightarrow-\mathrm{q}$. After it is found $\mathrm{v}_{3}(\mathrm{y})$, from (21) and (22) we will found $\mathrm{v}_{3}(\mathrm{y})$ accordingly in domains $\Omega_{31}$ and $\Omega_{32}$, hence in the domains of $\Omega_{31}$ and $\Omega_{32}$ the solution of problem III (III) is restored as the solution of problem Cauchy, and in the domains of $\Omega_{21}$ and $\Omega_{22}$ as the solution of problem Cauchy-Gaursat. The theorem 3 is proved. 
Citation: Kh AO (2014) Some Boundary Value Problems for the Hyperbolic: Hyperbolic type Equation with Two Line of Degeneration in Special Domain. J Appl Computat Math 3: 163 doi:10.4172/2168-9679.1000163

Page 4 of 4

\section{References}

1. Salakhitdinov MS, Urinov AK, Non-local boundary value problem for the equation with rough lines of degeneration.

2. Bitsadze AV (1953) To the problem of the mixed type equations. Trudi Instit Matem AN SSSR.

3. Bers $L$ (1958) Mathematical aspects of subsonic and transonic gas dynamics. Wiley, New 9 York.

4. Islomov B, Abdullayev OK (2009) Uniqueness of the solution of the boundary value problem for the degenerating equation of the hyperbolic-hyperbolic type on the third order in double-connected domain. Reports of the third congress of the world mathematical society of Turkic countries. Kazakhstan 316-320.

5. Salakhitdinov MS (1974) The equation of mixed and mixed-compound type.

6. Keldych MV (1951) On certain cases of degeneration of equations of elliptic type on the boundary of domain. Dokl Akad Nauk SSSR (NS) 77: 181-183.

7. Bitsadze AV (1964) Differetial equations of Mixed type. Mac Millan New York.

8. Abdullayev O Kh (2006) Boundary value problems for the mixed type equation of the third order with two lines perpendicular degeneration in doubleconnected. Doklady AN RUZ 7-11.

9. Smirnov MM (1985) Mixed type equations. The higher school.

10. Agmon S, Nirenberg L, Protter MH (1953) A maximum principle for a class of hyperbolic equation and application to equations of mixed elliptic-hyperbolic type. Communs Pure and Appl math 6: 455-470.

11. Gellerstedt $S$ (1937) Quelques problems mixtes pour L'eqaution $y^{m} z_{x x}+z_{y y}=0$ Arkhiv for Mat, Astr Och Fysik 1-32.

12. Tricomi $F$ (1947) About linear partial differential mixed type equations of the second order 190 . 